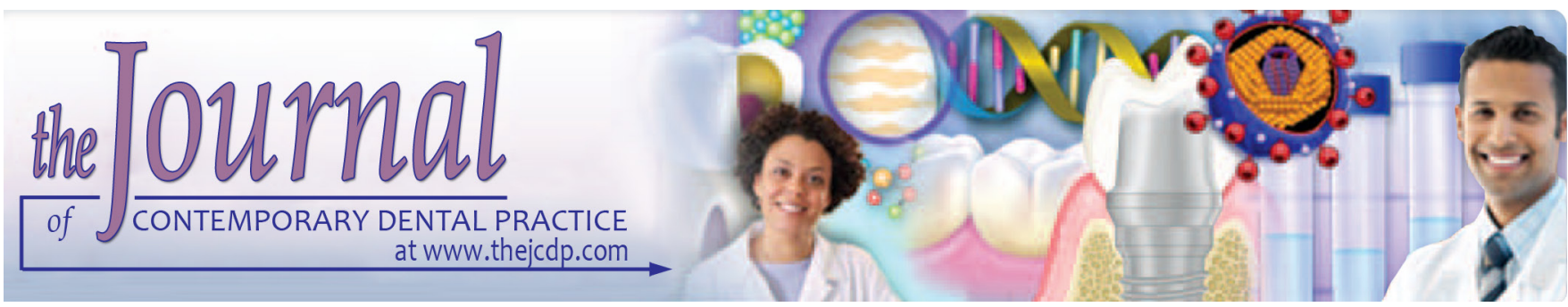

\title{
Cytotoxic and Genotoxic effect on the Buccal Mucosa Cells of Patients Undergoing Fixed Orthodontic Treatment
}

\author{
1 Junaid MH Kapadia, ${ }^{2}$ Anshu R Agarwal, ${ }^{3}$ Samvit Mishra, ${ }^{4}$ Purva Joneja, ${ }^{5}$ Asad S Yusuf, ${ }^{6}$ Deepak S Choudhary
}

\begin{abstract}
Aim: To evaluate the presence of metal ions and deoxyribonucleic acid damage on the cells of buccal mucosa in subjects scheduled to undergo fixed orthodontic treatment.

Materials and methods: Eighty patients scheduled to undergo orthodontic treatment were included in the present study. Samples were collected from buccal mucosa of the subjects at five different intervals: before the starting of the fixed appliance therapy, 5 months after the insertion of the appliance, 10 months after insertion of the appliance, 15 months after insertion of the appliance and 20 months after insertion of the appliance. Flow cytometry was further used for assessment of apoptosis. Comet assay was used for evaluating the metal ions associated deoxyribonucleic acid ((DNA) damage of buccal epithelial cells. Atomic absorption spectrometry was used for measuring the nickel (Ni), chromium $(\mathrm{Cr})$ and zinc $(\mathrm{Zn})$ levels in the cells of the buccal mucosa. Analysis of data was done by SPSS software version 16.0.
\end{abstract}

Results: A significant increase in the $\mathrm{Ni}, \mathrm{Cr}$ and $\mathrm{Zn}$ concentration during orthodontic treatment was observed. A progressive non-significant decrease in the percentage of viable cells from a baseline value to the end of the treatment was observed. A significant increase in the head diameter, DNA in tail and tail length, starting from the pretreatment value to the end of orthodontic treatment, was also observed.

Conclusion: Timely checking of deoxyribonucleic acid (DNA) damage and nuclear changes should be done for detecting earlier adverse changes.

Clinical significance: In patients wearing orthodontic appliances, no clinical impact occurs by wearing fixed appliances.

\footnotetext{
${ }^{1}$ Department of Public Health Dentistry, Bhabha College of Dental Sciences, Bhopal, Madhya Pradesh, India

${ }^{2-4,6}$ Department of Orthodontics and Dentofacial Orthopaedics, Bhabha College of Dental Sciences, Bhopal, Madhya Pradesh, India

${ }^{5}$ Department of Orthodontics and Dentofacial Orthopaedics, Institute of Dental Sciences, Barielly, Uttar Pradesh, India

Corresponding Author: Junaid MH Kapadia, Department of Public Health Dentistry, Bhabha College of Dental Sciences, Bhopal, Madhya Pradesh, India, Phone: +919501544877, e-mail: drjunaid.kapadia@gmail.com
}

Keywords: Chromium, Deoxyribonucleic acid (DNA) damage, Nickel, Orthodontic, Zinc.

How to cite this article: Kapadia JMH, Agarwal AR, Mishra S, Joneja P, Yusuf AS, Choudhary DS. Cytotoxic and Genotoxic effect on the Buccal Mucosa Cells of Patients Undergoing Fixed Orthodontic Treatment. J Contemp Dent Pract 2018;19(11):1358-1362.

Source of support: Nil

Conflict of interest: None

\section{INTRODUCTION}

Patients undergoing orthodontic treatment are often associated with various oral adverse effects, commonly, glositis, metallic taste, gingivitis, gingival hyperplasia, etc. Along with these effects, the release of metallic ions and corrosion products of the appliance used is also seen in patients undergoing orthodontic treatment. ${ }^{1,2}$

The orthodontic appliances remain in the mouth for an average time period of one and a half to two years, thereby providing a potentially corrosive environment by slow release of metallic ions. By directly integrating with DNA, these heavy metals can cause DNA damage. ${ }^{2,3}$ Literature quotes controversial findings in relation to the biocompatibility status of the orthodontic appliances. Some studies in the past literature have quoted the presence of the genotoxic effect of orthodontic alloys, while some other studies support the negative results.

In of the previous study conducted by Pereira et al., authors reported a decrease in the nuclear size of the buccal mucosa cells in response to the orthodontic bracket placement. However; the change reported by the authors was non-malignant. ${ }^{4-6}$ The single cell gel (comet) assay and the micronucleus $(\mathrm{MN})$ assay are the routinely used assays for the determination of the DNA damage. ${ }^{78}$ Under the light of above mentioned data, the present study was planned to assess the presence of metal ions and DNA damage in cells of the buccal mucosa in subjects scheduled to undergo fixed orthodontic treatment. 


\section{MATERIALS AND METHODS}

The present investigation was commenced in the department of orthodontics, and it included assessment of ion release and DNA damage in the cells of the buccal mucosa in patients undergoing fixed orthodontic treatment. Ethical approval was taken from the institutional ethical committee before the commencement of the study. Written consent from all the subjects was also obtained after explaining them in detail the entire research protocol. A total of 80 patients scheduled to undergo orthodontic treatment were included in the present study. Exclusion criteria for the present study included:

- Patients more than 38 years of age,

- Patients with a history of allergic reaction to artificial jewelry,

- Patients with a history of smoking,

- Patients who had a positive history of previous orthodontic treatment,

- Patients with the presence of metallic restorations Complete demographic and clinical details in all the patients were obtained before the starting of the treatment. Stainless steel fixed orthodontic treatment was carried out in all the patients using edgewise appliances.

\section{Sample Collection}

Using the Besaratinia et al. method, samples were collected from buccal mucosa of the subjects at five different intervals: before the starting of the fixed appliance therapy, 5 months after the insertion of appliance, 10 months after insertion of the appliance, 15 months after insertion of the appliance and 20 months after insertion of the appliance. ${ }^{9}$ Instructions were given to all the subjects to rinse the oral cavity with distilled water twice, for removing the dead epithelial cells. Using an interdental brush, epithelial cell sample collection was done from the buccal mucosa of the patients by gentle brushing. This was followed by centrifugation of the cells and their subsequent suspension in phosphate-buffered saline solution at a $\mathrm{pH}$ of 7.4. The solution was then filtered through polyamide gauze. Preparation of pelleted filtrate was done using centrifugation, followed by immediate re-suspension in $1 \mathrm{~mL}$ of phosphate-buffered saline solution. Placement of a hemocytometer (coated with trypan blue drop) on the binocular microscope was done, followed by focussing of the cells. Separate counting of both stained (nonviable) and unstained (viable) cells was done. ${ }^{10}$ Flow cytometry was further used for assessment of apoptosis. ${ }^{10,11}$ Comet assay was used for evaluating the metal ions associated DNA damage of buccal epithelial cells. Comet score software was used for assessment of apoptotic cell's head diameter. For calculating the amount of DNA damage, following parameters of the comet were assessed:

- Mean length of the tail,

- Percentage of DNA in tail, and

- Olive tail movement

Metal ions were estimated in the buccal mucosa cells using the method described previously in the literature. ${ }^{13}$ Atomic absorption spectrometry was used for measuring the Ni, $\mathrm{Cr}$ and $\mathrm{Zn}$ levels in the cells of the buccal mucosa. From each patient, out of the previously collected sample, $1 \mathrm{~mL}$ of cell suspension (100 cells) was obtained. The suspension was then treated with nitric acid (five percent concentration) and was diluted with distilled water. In between the concentration of $0.1 \mu \mathrm{g} / \mathrm{L}$ and $0.8 \mu \mathrm{g} / \mathrm{L}$, preparation of standard solutions of $\mathrm{Ni}, \mathrm{Cr}$, and $\mathrm{Zn}$ was done. Analysis of data was done by SPSS software version 16.0. Mann-Whitney U test and chi-square test were used for assessment of the level of significance. A p-value of less than 0.05 was taken as significant.

\section{RESULTS}

Total 80 patients with mean age of 13.5 years, scheduled to undergo orthodontic treatment were included in the present study. Mean concentration of $\mathrm{Ni}$ at baseline, after 5 months of placement of orthodontic appliances, after 10 months, after 15 months and after 20 months were found to be 22, 25.3, 39.1, 49.4 and 59.7 ppb respectively (Table 1 and Graph 1). Mean concentration of $\mathrm{Cr}$ at baseline, after 5 months of placement of orthodontic appliances, after 10 months, after 15 months and after 20 months were found to be 21.1, 25.3, 34.7, 43.9 and 55.4 ppb respectively (Table 1 and Graph 1). Mean concentration of $\mathrm{Cr}$ at baseline, after 5 months of placement of orthodontic appliances, after 10 months, after 15 months and after 20 months were found to be 194.6, 252.4, 328.7, 434.2 and $547.4 \mathrm{ppb}$ respectively (Table 1 and Graph 1). A significant increase in the $\mathrm{Ni}, \mathrm{Cr}$, and $\mathrm{Zn}$ concentration during orthodontic treatment was observed as shown in Table 1 ( $p<0.05)$. It has been found that there was a progressive nonsignificant decrease in the percentage of viable cells from a baseline value of 19.6 to a value of 9.7 at the end of the treatment (Table 2 and Graph 2). A significant increase in the head diameter, DNA in tail and tail length, starting from the pretreatment value to the end of orthodontic treatment, was also observed in the present study ( $p$-value <0.05). However; non-significant increase in the olive tail movement was observed in the present study (p-value $>0.05$ ) (Table 2).

\section{DISCUSSION}

In the routine orthodontic practice, a variety of metallic materials are used. Orthodontic wires and brackets 
Table 1: Comparison of metallic ions concentrations at different time intervals

\begin{tabular}{lllllll}
\hline & \multicolumn{7}{c}{ Time period } \\
\cline { 2 - 6 } Metallic ion & Baseline & After 5 months & After 10 months & After 15 months & After 20 months & p-value \\
\hline $\mathrm{Ni} \mathrm{(ppb)}$ & 22 & 25.3 & 39.1 & 49.4 & 59.7 & $0.02^{*}$ \\
$\mathrm{Cr}(\mathrm{ppb})$ & 21.1 & 25.3 & 34.7 & 43.9 & 55.4 & $0.01^{*}$ \\
Zn (ppb) & 194.6 & 252.4 & 328.7 & 434.2 & 547.4 & $0.02^{*}$ \\
\hline
\end{tabular}

*: Significant

Table 2: Comparison of Cytotoxicity and Genotoxicity at different time intervals

\begin{tabular}{lllllll}
\hline \multirow{2}{*}{$\begin{array}{l}\text { Cytotoxicity and } \\
\text { genotoxicity }\end{array}$} & After 5 months & After 10 months & After 15 months & After 20 months & $p$-value \\
\cline { 2 - 6 } Viable cells (\%) & 19.6 & 17.9 & 12.5 & 10.2 & 9.7 & 0.07 \\
Head diameter (px) & 110.5 & 139.4 & 156.8 & 163.1 & 180.2 & 0.00 \\
DNA in tail (\%) & 14.02 & 16.88 & 21.08 & 28.41 & 30.82 & 0.01 \\
Tail length (px) & 14.87 & 20.49 & 24.34 & 30.21 & 35.60 & 0.02 \\
Olive tail movement (px) & 6.99 & 7.21 & 10.77 & 12.38 & 14.51 & 0.09 \\
\hline
\end{tabular}

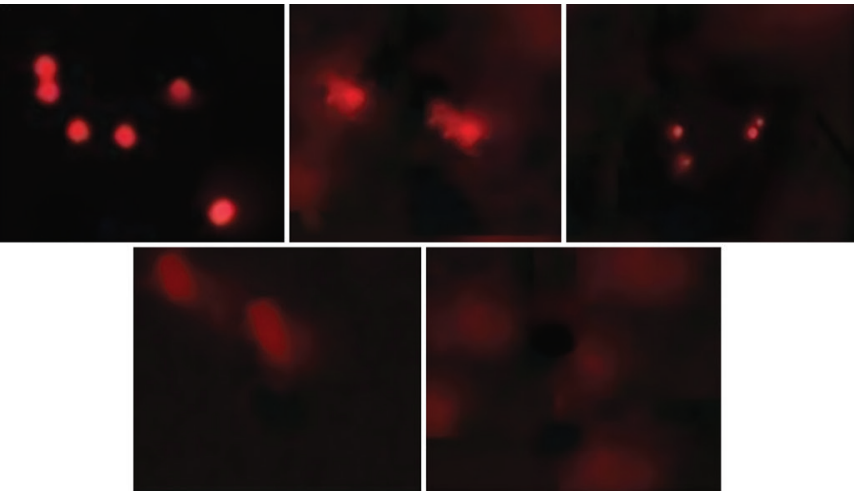

Graph 1: Metallic ions concentrations at different time intervals

contain stainless steel, and for connecting the supporting wires in orthodontic appliances, silver solder is the metal of choice. In the past few years, there has been extensive research in relation to the biocompatibility of the orthodontic materials. Previous authors have reported various hypersensitivity and allergic reactions against these orthodontic materials. ${ }^{12-14}$ Hence; the present study was planned to assess the presence of metal ions and DNA damage in cells of the buccal mucosa in subjects scheduled to undergo fixed orthodontic treatment.

In the present study, a steady increase in the $\mathrm{Ni}, \mathrm{Cr}$ and $\mathrm{Zn}$ ions concentrations during the entire time span of orthodontic treatment was observed, the results of which were found to be statistically significant ( $p$-value $<0.05$ ) (Table 1 and Graph 1). However; the levels of these ions did not reach the toxic level limit. Our results were in concordance with the results obtained by Amini et al., who also reported similar findings in their study. ${ }^{15}$

The current study revealed a non-significant decrease in the percentage viability of cells of buccal mucosa during the treatment. This further reinforces the theory that some quantity of cellular damage do occur in patients undergoing orthodontic treatment. Our results

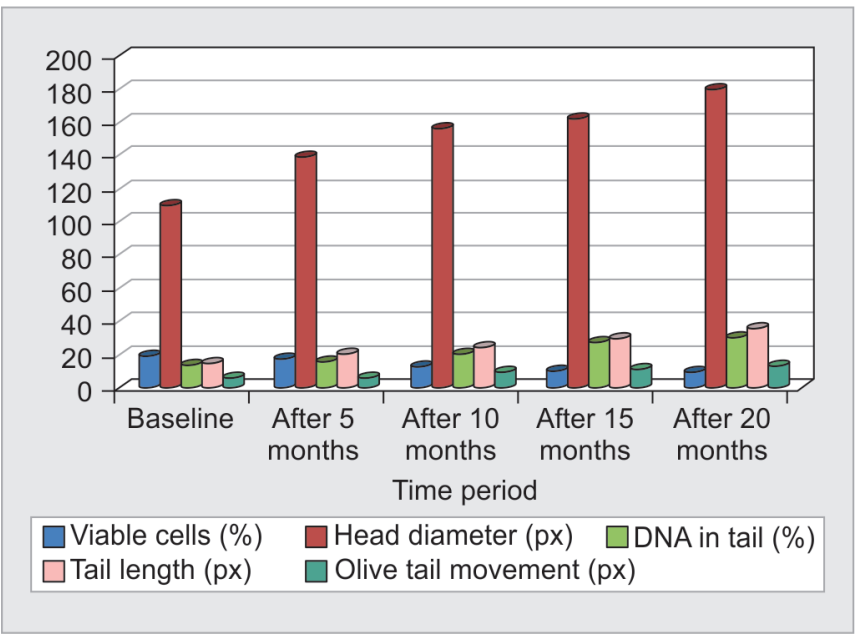

Graph 2: Cytotoxicity and genotoxicity at different time intervals

were in agreement with the results obtained by Guler et al., who reported similar findings in their study. ${ }^{16}$ In one of the previous study conducted by Gonçalves et al., authors assessed the cytotoxic and genotoxic effect of non-soldered bands (NSB) and silver soldered bands (SSB) on the $\mathrm{HepG}_{2}$ and HOK cell lines. They observed higher cytotoxicity and genotoxicity in SSB eluates in comparison to NSB samples. ${ }^{14}$

It has been observed that there was a significant higher level of apoptosis at the end of the orthodontic treatment in comparison to the pre-treatment values (Table 2 and Graph 2). This indicated that apoptosis of cells of buccal mucosa is induced by metallic ions released from the fixed orthodontic appliances. However; because of the continuous fundamental process of cell renewal going inside the human body, this failed to have any significant clinical effect. Heravi et al., in another study, assessed the genotoxic effect of orthodontic fixed appliances in 25 patients undergoing orthodontic treatment. They treated the patients with stainless steel orthodontic 
brackets and nickel-titanium arch wires. They assessed the oral mucosa cells twice; once before the starting of the treatment, and secondly nine months after the treatment. This was followed by centrifugation and dropping of the cells onto the slides. They used the micronuclei $(\mathrm{MN})$ assay for assessing the genomic alterations. They did not observe any significant difference in terms of the presence of a quantity of micronuclei in the buccal mucosa at two different time intervals. They concluded that fixed orthodontic therapy does not increase the risk of additional DNA damage in buccal mucosa cells of healthy individuals. ${ }^{17}$

In the present study, we also assessed the DNA damage by evaluating the length of the tail and percentage of DNA in the tail along with the olive tail movement of cells of the buccal mucosa. Figure 1 shows the results of the comet assay at different time intervals. With the course of time in patients undergoing orthodontic treatment, all the above-mentioned parameters showed a statistically significant increase. Similar results have been reported by Faccioni et al. ${ }^{18}$ In a study conducted by Westphalen GH; authors assessed the genotoxic effect of fixed orthodontic treatment in 20 patients with mean age of 16 years. They used MN assay and comet assay for evaluating the DNA damage in buccal mucosa cells. They did not observe any significant difference in the change in primary DNA damage levels in patients undergoing orthodontic treatment. ${ }^{19}$ Hafez et al. assessed cytotoxic and genotoxic effect of fixed orthodontic appliances in patients undergoing orthodontic treatment. They assessed 18 controls and 28 treated subjects. They tested four combinations of brackets and arch wires. Collection of buccal mucosa samples was done in their study at three different time intervals; pretreatment, 3 months and 6 months after placement of fixed orthodontic appliances. They observed a decrease in cellular viability, DNA damage (orthodontic appliance induced) and elevated content of $\mathrm{Ni}$ and $\mathrm{Cr}$ in the buccal mucosa cells, under the effect of fixed orthodontic appliances. $^{8}$

Past studies have reported various controversial results which can be due to several other additional factors. There was a difference in the time period of appliance placement in all the previous studies. Some assessed the DNA damage at the time of appliance debonding, ${ }^{20}$ while others assessed the DNA damage 10 to 30 days after placement of orthodontic appliances. ${ }^{21}$ Several other studies have also reported the release of metallic ions from the orthodontic appliances. However; quantity of these metallic ions has been found to be far away from the toxic range. 22,23

The standard alkaline solution used in the comet assay gives minimal knowledge concerning the type of DNA damage, as it is almost impossible to know whether the breaks detected in the DNA strand are the result of direct effect of orthodontic appliances or due
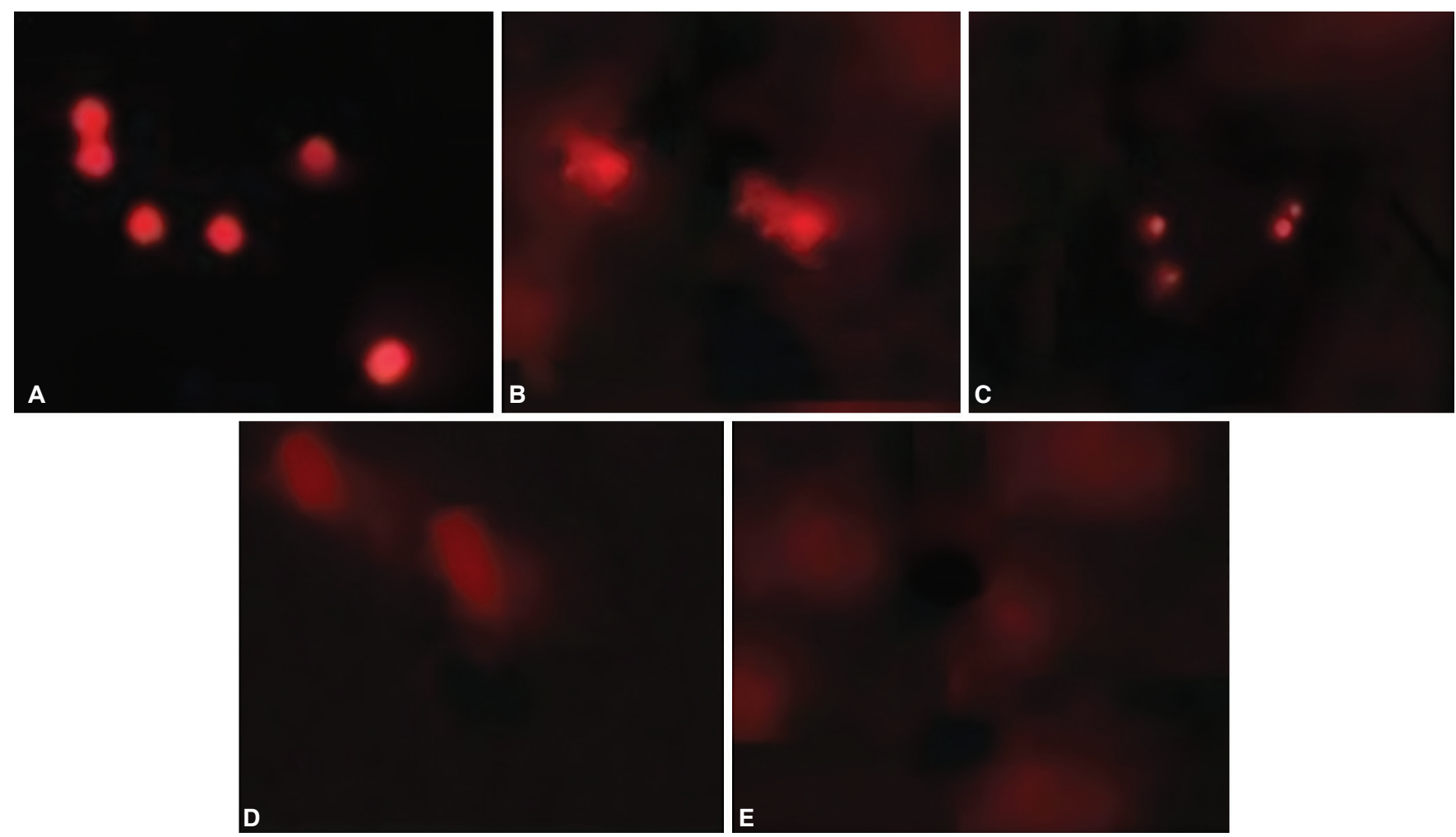

Figs $1 \mathrm{~A}$ to $\mathrm{E}$ : Damaged cells are seen as comets when comet assay was performed.y (A) Before insertion of the appliance; (B) After 5 months; (C) After 10 months; (D) After 15 months years, and; (E) After 20 months 
to indirect oxidative damage. Hence; further research is warranted. ${ }^{14}$

\section{CONCLUSION}

Increase in metal ions in cells of buccal mucosa in patients undergoing fixed orthodontic treatment occur within physiologic dietary limits. Some quantity of DNA damage also occurs in these patients. Therefore, we strongly recommend that timely checking of DNA damage and nuclear changes should be done in patients undergoing orthodontic treatment so that adverse changes if occur, could be detected at the earliest.

\section{REFERENCES}

1. Mockers O, Deroze D, Camps J. Cytotoxicity of orthodontic bands, brackets and arch wires in vitro. Dent Mater 2002;18:311-317.

2. Lindsten R, Kurol J. Orthodontic appliances in relation to nickel hypersensitivity: a review. J OrofacOrthop 1997;58: 100-108.

3. Starkjaer L, Menne T. Nickel allergy and orthodontic treatment. Eur J Orthod 1990;12:284-289

4. Eliades T, Pratsinis H, Kletsas D, Eliades G, Makou M. Characterization and cytotoxicity of ions released from stainless steel and nickel-titanium orthodontic alloys. Am J Orthod Dentofacial Orthop. 2004 Jan;125(1):24-29.

5. Tomakidi P, Koke U, Kern R, Erdinger L, Kruger H, Kohl A. Assessment of acute cyto- and genotoxicity of corrosion eluates obtained from orthodontic materials using monolayer cultures of immortalized human gingival keratinocytes. J Orofac Orthop. 2000;61(1):2-19.

6. Pereira BR, Tanaka OM, Lima AA, Guariza-Filho O, Maruo $\mathrm{H}$, Camargo ES. Metal and ceramic bracket effects on human buccal mucosa epithelial cells. Angle Orthod. 2009 Mar;79(2):373-379.

7. Heravi F, Abbaszadegan MR, Merati M, Hasanzadeh N, Dadkhah E, Ahrari F. DNA Damage in Oral Mucosa Cells of Patients with Fixed Orthodontic Appliances. J Dent (Tehran, Iran). 2013;10(6):494-500.

8. Hafez HS, Selim EM, Kamel Eid FH, Tawfik WA, Al-Ashkar EA, Mostafa YA. Cytotoxicity, genotoxicity, and metal release in patients with fixed orthodontic appliances: a longitudinal in-vivo study. Am J Orthod Dentofacial Orthop. 2011 Sep;140(3):298-308.

9. Besaratinia A, Van Straaten HW, Godschalk RW, Van Zandwijk N, Balm AJ, Kleinjans JC, et al. Immunoperoxidase detection of polycyclic aromatic hydrocarbon-DNA adducts in mouth floor and buccal mucosa cells of smokers and non smokers. Environ Mol Mutagen 2000;36:127-133.
10. Hartmann A, Speit G. The contribution of cytotoxicity to DNA-effects in the single cell gel test (comet assay). Toxicol Lett 1997;90:183-188.

11. Duensing TD, Watson SR. Assessment of Apoptosis (Programmed Cell Death) by Flow Cytometry. Cold Spring Harb Protoc. 2018 Jan 2;2018(1):pdb.prot093807.

12. Gyori BM, Venkatachalam G, Thiagarajan PS, Hsu D, Clement $\mathrm{M}-\mathrm{V}$. OpenComet: An automated tool for comet assay image analysis. Redox Biology. 2014;2:457-465.

13. Schmalz G, Garhammer P. Biological interactions of dental cast alloys with oral tissues. Dent Mater. 2002; 18(5): 396-406.

14. Gonçalves TS, Menezes LM, Trindade C, Machado Mda S, Thomas P, Fenech M et al. Cytotoxicity and genotoxicity of orthodontic bands with or without silver soldered joints. Mutat Res Genet Toxicol Environ Mutagen. 2014;762: 1-8.

15. Amini F, BorzabadiFarahani A, Jafari A, RabbaniM. In vivo study of metal content of oral mucosa cells in patients with and without fixed orthodontic appliances. Orthod Craniofac Res 2008;11:51-56.

16 Guler C, Toy E, Ozturk F, Gunes D, Karabulut AB, Otlu O, et al. Evaluation of salivary total oxidant-antioxidant status and DNA damage of children undergoing fixed orthodontic therapy. Angle Orthod 2015;85:239-244.

17. Heravi F, Abbaszadegan MR, Merati M, Hasanzadeh N, Dadkhah E, Ahrari F. DNA Damage in Oral Mucosa Cells of Patients with Fixed Orthodontic Appliances. J Dent (Tehran, Iran). 2013;10(6):494-500.

18. Faccioni F, Franceschetti P, Cerpelloni M, Fracasso ME. In vivo study on metal release from fixed orthodontic appliances and DNA damage in oral mucosa cells. Am J Orthod Dentofacial Orthop 2003;124:687-693

19. Westphalen GH, Menezes LM, Prá D, Garcia GG, Schmitt VM, Henriques JA, Medina-Silva R. In vivo determination of genotoxicity induced by metals from orthodontic appliances using micronucleus and comet assays. Genet Mol Res. 2008;7(4):1259-1266.

20. Natarajan M, Padmanabhan S, Chitharanjan A, Narasimhan M. Evaluation of the genotoxic effects of fixed appliances on oral mucosal cells and the relationship to nickel and chromium concentrations: an in-vivo study. Am J Orthod Dentofacial Orthop. 2011 Sep;140(3):383-388.

21. Fernandez-Minano E, Ortiz C, Vicente A, Calvo JL, Ortiz AJ. Metallic ion content and damage to the DNA in oral mucosa cells of children with fixed orthodontic appliances. Biometals 2011 Oct;24(5):935-941.

22. Bishara SE, Barrett RD, Selim MI. Biode-gradation of orthodontic appliances. Part II. Changes in the blood level of nickel. Am J Orthod Dentofacial Orthop. 1993 Feb;103(2): 115-119.

23. Eliades T, Trapalis C, Eliades G, Katsavrias E. Salivary metal levels of orthodontic patients: a novel methodological and analytical approach. Eur J Orthod. 2003 Feb;25(1):103-106. 